\title{
Transmission Mechanism of Stock Price Fluctuation in the Rare Earth Industry Chain
}

\author{
Yanjing Jia ${ }^{1} \mathbb{C}$, Chao Ding ${ }^{2, *}$ and Zhiliang Dong ${ }^{3,4,5}$ \\ 1 School of Urban Geology and Engineering, Hebei GEO University, Shijiazhuang 050031, China; \\ jyj07060145@163.com \\ 2 School of Management, Hebei GEO University, Shijiazhuang 050031, China \\ 3 Strategy and Management Base of Mineral Resources in Hebei Province, Hebei GEO University, \\ Shijiazhuang 050031, China; dongzhl@126.com \\ 4 Key Laboratory of Intelligent Detection and Equipment for Underground Space of Beijing-Tianjin-Hebei \\ Urban Agglomeration, Ministry of Natural Resources, Shijiazhuang 050031, China \\ 5 Natural Resource Asset Capital Research Center, Hebei GEO University, Shijiazhuang 050031, China \\ * Correspondence: hd8516@163.com
}

Citation: Jia, Y.; Ding, C.; Dong, Z. Transmission Mechanism of Stock Price Fluctuation in the Rare Earth Industry Chain. Sustainability 2021, 13, 12913. https://doi.org/10.3390/ su132212913

\section{Academic Editors: Yi Liang,}

Dongxiao Niu, Wei-Chiang Hong and Mengjie Zhang

Received: 26 October 2021

Accepted: 20 November 2021

Published: 22 November 2021

Publisher's Note: MDPI stays neutral with regard to jurisdictional claims in published maps and institutional affiliations.

Copyright: (c) 2021 by the authors. Licensee MDPI, Basel, Switzerland. This article is an open access article distributed under the terms and conditions of the Creative Commons Attribution (CC BY) license (https:// creativecommons.org/licenses/by/ $4.0 /)$.

\begin{abstract}
The transmission of stock price fluctuations of listed companies in the rare earth industry has complex characteristics. Mastering its transmission law is of great meaning to understand the relationship between the upstream and downstream of the rare earth industry chain and market investment. This article uses the time series of daily closing prices of stocks in the global rare earth industry chain in the past ten years as the research object. The Granger causality test and complex network theory were used to construct the risk transmission network of the industrial chain. We have identified the key stocks in the network of stock price fluctuation in the rare earth industry chain and obtained the transmission path of stock price fluctuation. According to the results: (1) The stocks of Chinese and Japanese listed companies considerably influence the transmission of the stock price fluctuation in the rare earth industry chain. (2) The transmission distance of the stock price fluctuation of each network is relatively small, and the transmission speed is relatively fast. (3) The fluctuation of stock price in the rare earth industry chain is mainly transmitted from the upstream and midstream links to the midstream and downstream links.
\end{abstract}

Keywords: rare earth; industry chain; complex network; Granger causality test; maximum spanning tree

\section{Introduction}

Rare earth materials are strategic resources known as "industrial vitamins". These materials are separated into light and heavy rare earth materials according to the differences in the mineral characteristics. Rare earth materials are used in the military [1], metallurgical [2], petrochemical [3], and other fields; consequently, the development of the rare earth industry is crucial for the evolution of modern industries. The rare earth industry chain involves a group of rare earth enterprises with certain internal connections. The upstream, midstream and downstream links of the industrial chain are responsible for the progress of the rare earth ore, rare earth smelting and separation, and deep processing and application. An exchange of relationships and mutual values occurs between all links. The upstream links provide products or services to the midstream and downstream links, and then information is fed back upstream from downstream. Changes in any link affect the development direction of the industry chain and the decisions of investors and consumers. The stock price is the "barometer" of the macro-economy. The study of the fluctuation transmission mechanism of the stock prices of listed companies upstream, midstream, and downstream of the rare earth industry chain has two functions. First, the transmission mechanism of the stock price fluctuation in the rare earth industry chain can be comprehensively analyzed. We can also identify stocks that have a key conduction effect in the rare earth industry 
chain. Moreover, such an analysis can provide a reference for market participants in the rare earth industry chain to prevent and control the market fluctuation risks and assist rare earth-related companies and investors in making reasonable investment decisions.

The current research on rare earth materials is mainly focused on the global rare earth resource exploitation [4-6], China's rare earth industrial policy [7-9], and supply chain in the rare earth industry chain [10-12].

The idea of the industrial chain comes from Adam Smith. Hirschman used this idea to analyze the impact of forward and backward linkages between enterprises on economic development [13]. Porter studied the relationship between manufacturers in different links of the industrial chain from the perspectives of the value chain and cost chain [14]. Steven further expanded the meaning of the industrial chain. He introduced the logistics chain and information chain into the industrial chain composed of manufacturers, suppliers, distributors, and consumers [15]. It is now generally believed that the industrial chain is a notion that includes four scales, namely, the value chain, enterprise chain, supply chain, and space chain. The current research on the industrial chain is mainly divided into research based on the value chain $[16,17]$ and based on the supply chain $[18,19]$.

The current research on the rare earth industry chain focuses on the supply chain, with an emphasis on the analysis and prediction of the supply and demand status of rare earth materials. Wang X B used the generalized Weng model to predict the output of the three rare earth materials mainly produced in China (mixed rare earth, bastnasite, and ionabsorbed rare earth) [20]. Ge J P constructed a dynamic computable equilibrium (DCGE) model to predict China's rare earth production, domestic supply and exports in 2025 [21]. Wang X B predicted China's rare earth element production trend and the Hubbert peak, and the results showed that China's rare earth element production will peak by 2040 and gradually decline [22]. These studies provide a reference for the sustainable development of rare earth element markets and rare-earth-related industries in China and the world. In addition, Samsonov N Y analyzed the results of the global supply chain management methods of rare earths and rare metals in the United States, the European Union, and Russia as factors influencing the spatial distribution of international cooperation [23].

At present, the research on the industrial chain has begun to expand to the financial field, and the correlation between stock price fluctuations is used to reflect the correlation between the industrial chains. It mainly reflected the relationship with the supply and demand chain in the industrial chain, Liu J X discussed the impact of supply chain disruption on the stock market of Japanese listed companies [24]. Wang Y discussed the relationship between stock management and supply chain management [25].

With the continuous development of the rare earth industry, the rare-earth-related financial market has also attracted the attention of scholars. Mainly focused on the relationship between the rare earth market and other markets. Reboredo J C used a Markov switching vector autoregressive model to analyze the price spillover between rare earth stocks and financial markets [26]. Chen $\mathrm{Y}$ investigated the fluctuation spillover and dynamic correlation between international crude oil, new energy, and Chinese rare earth markets [27]. Bouri E analyzed the dynamics of return and volatility connectedness between the rare earth stock index and indices of clean energy, consumer electronics, telecommunications, healthcare equipment, aerospace, and defense [28]. The results indicated that extreme market scenarios considerably influence the earnings and volatility connectivity dynamics. Zheng B A studied the asymmetric connectivity and dynamic spillovers of China's renewable energy and rare earth markets and described the risk transfer between renewable energy and rare earth market companies in the form of network connectivity [29].

The complex network method has been widely used in trade [30], energy [31], finance [32], and other fields. This method is used to analyze the overall structure, correlation mechanism, conduction path, and other relationships among a large number of variables. Granger causality test analyzes the causal relationship between variables from the perspective of prediction and is often used in biological sciences [33], social sciences [34], finance [35], and other fields. B Algieri used Granger causality test to analyze the relation- 
ship between stock market volatility, speculation, and unemployment. The result negated the traditional present value model (PVM) and provided new elements for the possible determinants of stock price fluctuations. It is verified that the Granger causality test is advanced in the research of stock price fluctuation [36]. Several scholars have combined the two methods. Specifically, the researchers used the Granger causality test method to identify the relationships among the time series and later used the complex network theory to map these relationships to the network. For example, Sun Q R constructed a price index Granger causality network to analyze the volatility transmission path of a certain price index [37]. Huang C X ranked the influence nodes of China's A-share market. In the rare earth stock market, the interconnections among stocks lead to the generation of a complex system [38]. Therefore, to study the fluctuation transmission mechanism among the stock prices of listed companies upstream, midstream, and downstream of the rare earth industry chain, it is necessary to use the Granger causality test to identify the relationships among the stocks. Next, we used the stocks as nodes and the Granger causality among the stocks as edges to construct a transmission network of the stock price fluctuation in the rare earth industry chain.

According to the above-mentioned studies, the current research on the rare earth industry chain and rare earth stock market is relatively separate. Most studies on the rare earth stock market focus on the spillover effects of stock price fluctuation between the rare earth stock market and other markets. The emphasis is on the mutual influence of investment in different markets rather than the investment in the rare earth market. Therefore, research on the stock market associated with the rare earth industry is limited. From the perspective of the rare earth industry chain, this paper examines the fluctuation transmission mechanism of the stock prices of listed companies upstream, midstream, and downstream of the rare earth industry chain. Using the correlation of stock price fluctuations to reflect the correlation between various links of the industrial chain. The objective is to provide a reference for market participants in the rare earth industry to prevent and control market fluctuation risks.

The article is organized as follows. A directional transmission network of the stock price fluctuation in the rare earth industry chain was constructed. Considering the transmission capacity of stock price fluctuation, transmission medium capacity, transmission cohesion, and transmission distance, the stocks that are in key transmission positions in the rare earth industry chain were determined. The CONCOR method and the maximum spanning tree method were used to identify the conduction path. It is hoped that the findings can help market participants in the rare earth industry chain prevent and control market fluctuation risks and provide a reference for investors to make reasonable investment decisions.

\section{Materials and Methods}

\subsection{Data Source and Preprocessing}

The wind database is the core database in the field of financial data. The industry chain platform provides industrial chain maps and related data that the market emphasizes. The research object in this study is the time series of daily closing prices of the rare earth industry chain stocks from 4 January 2011 to 31 December 2020. After removing the companies listed and delisted in the selected years, we retained 7, 24, and 20 stocks in the industrial chain and middle and downstream links. In constructing the whole network, the data of stocks in multiple links such as 600111.SH (China) and 600549.SH (China) were retained only once. The links in which these stocks are located were divided into upstream, midstream, and downstream, as well as upper and middle reaches and middle and lower reaches. Finally, we obtained 44 stocks in the whole industrial chain, with each stock corresponding to 2432 valid data points. The links in the industrial chain of each stock are shown in Figure 1. The upstream, midstream, and downstream links are responsible for the development of rare earth ore, rare earth smelting and separation, and its deep processing and application. 


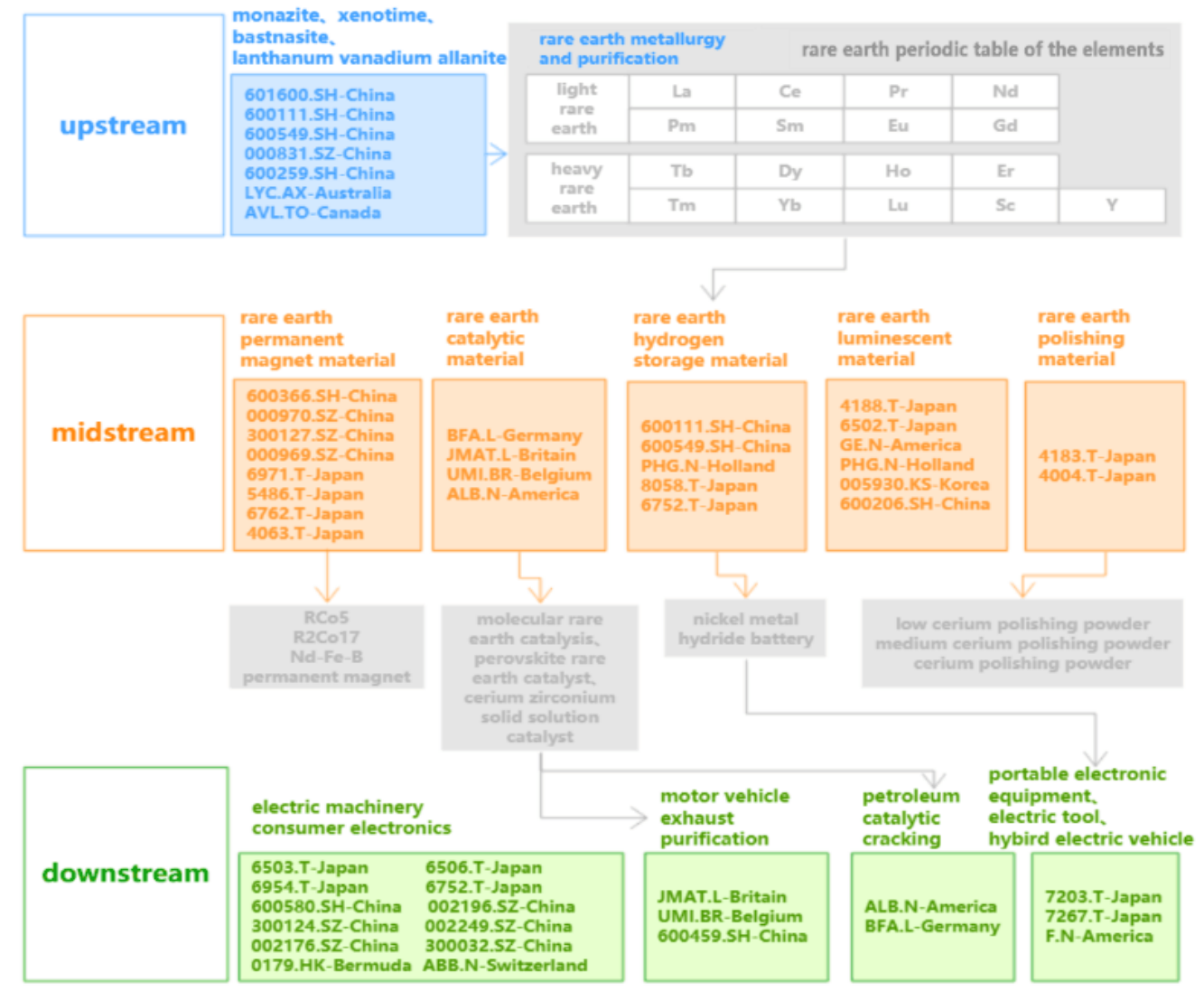

Figure 1. The position of each stock in the industrial chain.

To accurately represent the stock price changes, the data were normalized using Equation (1).

$$
\mathrm{x}^{\prime}=\frac{\mathrm{x}-\mathrm{x}_{\min }}{\mathrm{x}_{\max }-\mathrm{x}_{\min }}
$$

In the formula, $\mathrm{x}$ is the closing price of the original stock, $\mathrm{x}_{\text {min }}$ represents the minimum value of the stock data, $x_{\max }$ represents the maximum value, and $x^{\prime}$ is the normalized data point.

The Granger causality test requires the time series to be a stationary time series. We used the augmented Dickey-Fuller (ADF) test to ensure the stationarity of the time series, using the following expression.

$$
x_{t}=\alpha+\beta t+\gamma x_{t-1}+\sum_{i=1}^{p-1} \alpha_{i} \Delta x_{t-i}+\varepsilon_{t}
$$

In the formula, $x_{t}$ is the time series of the stock closing prices, $\Delta x_{t}$ is the first-order difference, and $\varepsilon_{\mathrm{t}}$ represents the error term. The null hypothesis of the ADF test is $\mathrm{H}_{0}: \gamma=0$. Accepting or rejecting the null hypothesis means that the time series is nonstationary or stationary, respectively.

\subsection{Methodology}

\subsubsection{Construction of the Network Model}

1. Granger causality test.

The Granger causality test is used to analyze the causal relationship between variables from the perspective of prediction [39]. Given two stationary time series $X_{t}$ and $Y_{t}$, the 
autoregressive model $r$ of $Y_{t}$ is defined as in Equation (3), and the prediction model $u$ of $Y_{t}$ with the lagged variable of $X_{t}$ is defined as in Equation (4).

$$
\begin{gathered}
Y_{t}=\alpha_{0}+\sum_{i=1}^{p} \alpha_{i} Y_{t-i}+\varepsilon_{t} \\
Y_{t}=\alpha_{0}+\sum_{i=1}^{p} \alpha_{i} Y_{t-i}+\sum_{i=1}^{q} \beta_{i} X_{t-i}+\varepsilon_{t}
\end{gathered}
$$

In the formula, $\alpha_{0}$ is a constant term, $\mathrm{p}$ and $\mathrm{q}$ represent the maximum lag periods of the variables $X_{t}$ and $Y_{t}$, respectively, $\alpha_{i}$ and $\beta_{i}$ are regression coefficients, and $\varepsilon_{t}$ is an error term. The null hypothesis " $\mathrm{H}_{0}: \beta_{1}=\beta_{2}=\ldots=\beta_{\mathrm{q}}=0$ " means that $X_{\mathrm{t}}$ is not the cause of the change in $Y_{t}$, and the $F$ statistic is defined as shown in Equation (5).

$$
\mathrm{F}=\frac{\left(\mathrm{RSS}_{\mathrm{r}}-\mathrm{RSS}_{\mathrm{u}}\right) / \mathrm{q}}{\mathrm{RSS}_{\mathrm{u}} /(\mathrm{n}-\mathrm{p}-\mathrm{q}-1)} \sim \mathrm{F}(\mathrm{q}, \mathrm{n}-\mathrm{p}-\mathrm{q}-1)
$$

In the formula, RSS $r$ and RSS $_{u}$ represent the residual sum of squares of the abovementioned two models, and $\mathrm{n}$ is the sample size. For a given significance level $\alpha$ (this paper selects 0.01 as the significance level), if $F \geq F_{\alpha}(q, n-p-q-1), \beta_{1}, \beta_{2}, \ldots, \beta_{q} \neq 0$, and we rejected $t$ the null hypothesis such that $X_{t}$ is the cause of the change in $Y_{t}$; otherwise, were accepted the null hypothesis of $X_{t}$ not being the cause of the change in $Y_{t}$.

The data of 7 stocks upstream of the rare earth industry chain, 24 stocks midstream, 20 stocks downstream, and 44 stocks (there are 44 stocks in total, not 51 because some stocks are common to different streams) in the whole industrial chain were considered to perform Granger causality tests in pairs. Subsequently, we obtained the Granger causality matrix between each pair of stocks of the four groups. If a causal relationship exists between two stocks, the test result is 1 ; otherwise, the result is 0 .

2. Complex network theory.

A complex network requires two basic elements of nodes $(\mathrm{M})$ and edges $(\mathrm{N})$ to construct a model $\mathrm{F}=(\mathrm{M}, \mathrm{N})$. Each stock was considered as the node of the network, and the Granger causality between the stocks is considered as the edge between the nodes to construct a directed complex network. If stock $\mathrm{A}$ is the Granger cause of stock $\mathrm{B}, \mathrm{a}$ directed edge exists between $A$ and $B$, starting from $A$ and ending at B. If no Granger cause exists between the two nodes, no edge exists. By implementing these steps, the Granger causality between the stocks in the rare earth industry chain was reflected in the complex network. This paper constructs upstream, midstream, and downstream stock price fluctuation correlation subnetworks and a group of whole networks.

3. CONCOR iterative correlation convergence method.

After determining the Granger causality matrix among stocks, the CONCOR method was used to divide the matrix into independent submatrices, also known as "blocks". The relationship between the nodes in each submatrix is strong, and the relationship between each submatrix can be analyzed. The basic working principle of CONCOR is as follows: first, the correlation coefficient between the rows (or columns) of the matrix needs to be calculated to obtain the correlation coefficient matrix C1. Subsequently, the correlation coefficients between the rows (or columns) of $\mathrm{C} 1$ need to be calculated to obtain the correlation coefficient matrix $\mathrm{C} 2$. The calculation was iteratively performed, and finally, a matrix with a correlation coefficient of 1 or -1 was obtained. The system simplifies the matrix of the iterative process to obtain the partition of each stock. Subsequently, according to the density table and $\alpha$-density index, we can obtain the density table between blocks. Finally, we could obtain a highly generalized image matrix and draw a simplified diagram to study the risk transmission path of the stock price fluctuation. 


\section{Maximum spanning tree model.}

The maximum spanning tree is the connected graph with the shortest connection path of all nodes in the network, and it is the connected graph with the largest edge weight. The propagation path of stock price fluctuation is usually from the country that sends the fluctuation to the most closely related country, which also means that there is the shortest and fastest path to all nodes, that is, the largest spanning tree graph. Therefore, the maximum spanning tree model can identify the transmission path of stock price fluctuation for the reference of rare earth market participants and investors. This paper adopts the Kruskal algorithm (Joseph Kruskal, 1956) to construct the maximum spanning tree. The basic principle is: first, all the points in the graph are regarded as isolated branches, and the edges in the graph are sorted according to their weights. Traverse the graph once to find the edge with the largest weight, and ensure that the edge found this time cannot form a loop with the edge that has been added to the largest spanning tree set. If the conditions are met, this edge is added to the maximum spanning tree set. If the conditions are not met, continue to traverse the graph to find the next edge with the largest weight. Repeat the above steps until n-1 edges are found (if there are n nodes in the graph, the maximum spanning tree should have n-1 edges), the algorithm ends, and the maximum spanning tree corresponding to the graph is obtained. The stock price fluctuation network in this paper is a directed and unweighted network, and the maximum spanning tree model is only used to identify the connected graph with the shortest path without considering the weight of the edge.

\subsubsection{Construction of the Transmission Network}

We performed an ADF test on the data of the 44 stocks, and stable time series were obtained after the first-order difference was implemented. We performed a Granger causality test on the time series after applying the first-order difference to obtain the Granger causality between any two stocks. Next, we considered the stocks as nodes and Granger causality between stocks as edges to construct a directional transmission network of the stock price fluctuation in the rare earth industry chain. A total of 44 nodes and 399 edges exist in the transmission network of the stock price fluctuation of the whole rare earth industry chain. The networks upstream, midstream, and downstream of the industrial chain have 7, 23, and 20 nodes and 15, 115, and 96 edges, respectively. No Granger causality relationship exists between 300127.SZ (China) and any other stock in the midstream link; thus, the number of network nodes in the midstream link is 23 . The network diagram of each link is shown in Figure 2. The blue nodes correspond to the upstream stock, the purple nodes correspond to the upstream and midstream shared stock, the orange nodes correspond to the midstream stock, the yellow nodes correspond to the midstream and downstream shared stock and the green nodes correspond to the downstream stock (The meaning of the color of the nodes in the network diagram in the follow-up of the article is the same). In terms of the scale of the subnetwork, the largest and smallest scales correspond to the midstream rare earth smelting link and upstream rare earth mining development link, respectively. The connections between nodes in the four groups of networks are relatively complex, and no isolated nodes exist except for those in the midstream network, indicating that these networks have high connectivity.

Figure 3 shows the transmission network between the upstream, midstream, and downstream layers of the transmission network of the stock price fluctuation in the rare earth industry chain. The figure intuitively shows the Granger causality transfer relationship within and among the upstream, midstream, and downstream links of the industrial chain. Moreover, the figure shows that the stock price fluctuation of any stock in the rare earth industry chain may affect other stocks in the industry chain. 
(a)

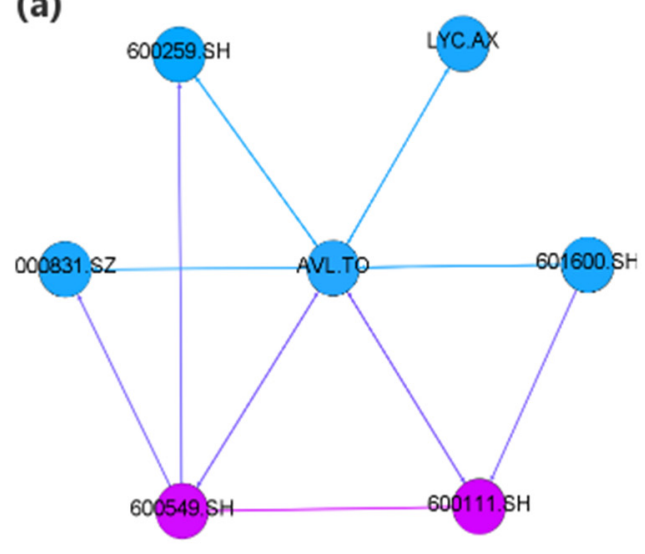

(c)

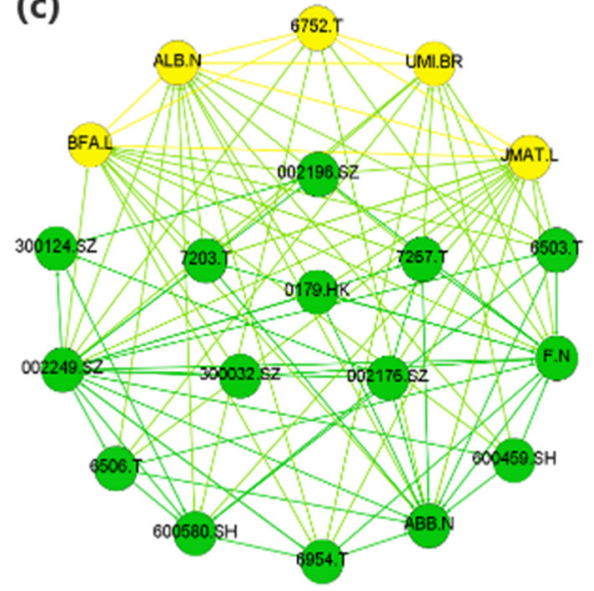

(b)
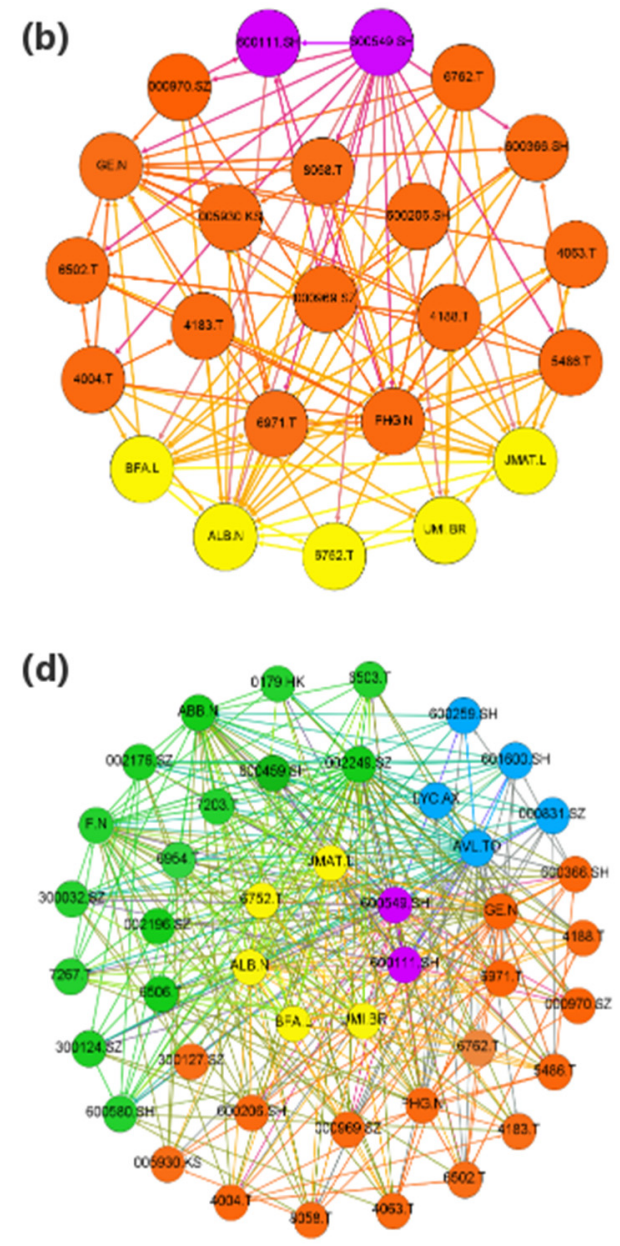

Figure 2. Transmission networks of stock price fluctuation of the rare earth industry chain. Note: (a) the network in the upstream of the industry chain; (b) the network in the midstream of the industry chain; (c) the network in the downstream of the industry chain; (d) the network of the whole industry chain.

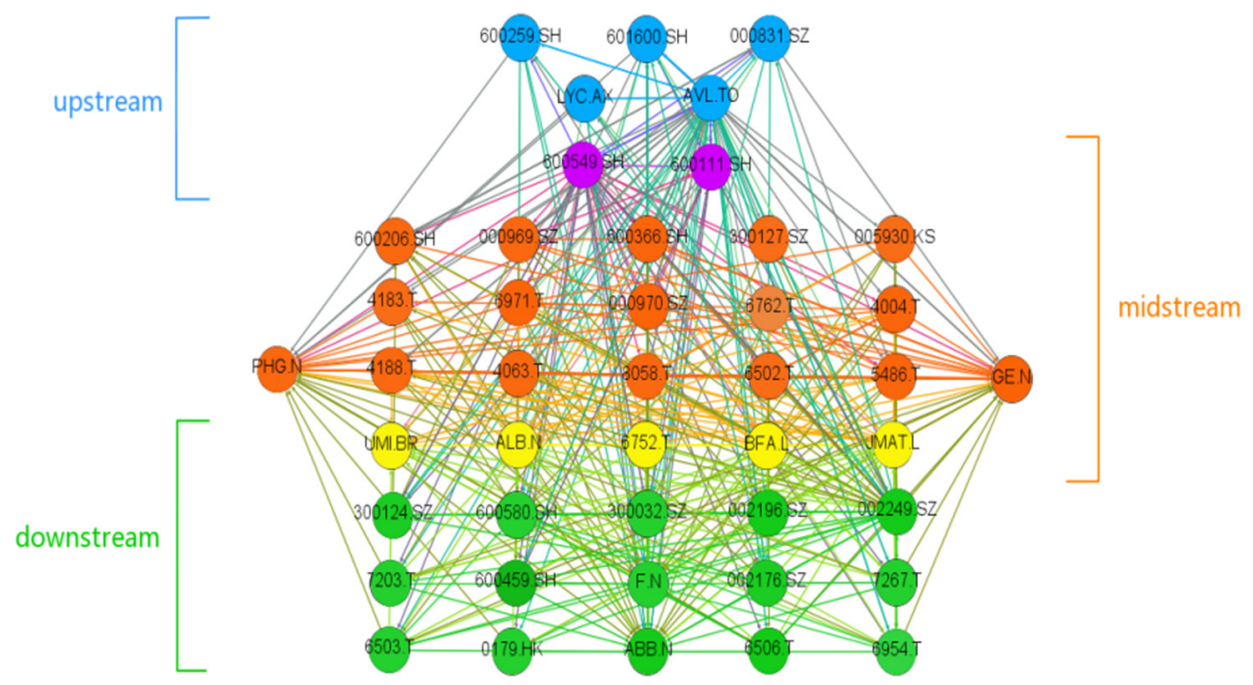

Figure 3. The transmission network of stock price fluctuation between the upstream, midstream and downstream of the rare earth industry chain. 


\subsubsection{Topological Structure of the Network}

1. Transmission ability of the stock price fluctuation.

In the transmission network of the stock price fluctuation in the rare earth industry chain, the node degree of a stock represents the Granger causality between the stock and other stocks. A stock's out-degree indicates the number of Granger causes that the stock serves as other stocks, which means how many other stocks will the stock price fluctuation of one stock cause. It could be used to express the transmission ability of the stock's price fluctuation. A larger out-degree corresponds to a greater transmission capacity of the stock price fluctuation. Similarly, a stock's in-degree indicates the number of Granger causes that the stock serves as other stocks, which means the stock price of a stock will be affected by the stock price fluctuations of how many other stocks. It could be used to express the degree of exposure of the stock to fluctuation in other stock prices. A larger in-degree corresponds to a more notable exposure of the stock to fluctuation in other stock prices. The formulas of the out-degree and in-degree are shown in Equations (6) and (7), respectively [40].

$$
\begin{aligned}
& D_{\text {out }}(i)=\sum_{i=1}^{n} \sum_{j=1}^{n} G_{i j} \\
& D_{\text {in }}(i)=\sum_{i=1}^{n} \sum_{j=1}^{n} G_{j i}
\end{aligned}
$$

where $i$ and $j$ are stocks; $G_{i j}=1$ means that $i$ is the Granger cause of $j$; and $G_{i j}=0$, means that $i$ is not the Granger cause of $j$.

2. Transmission medium capacity of stock price fluctuation.

The ability of a medium for stock price fluctuation transmission can be described by the betweenness centrality of the node. The betweenness centrality of a node in the network measures the degree to which a node controls the resources and can indicate the degree to which the node controls the interactions of other nodes, which could indicate the extent to which the stock is a stock through which the stock price fluctuation of one stock must be transmitted to another stock. The betweenness centrality can be defined as in Equation (8).

$$
B_{i}=\frac{\sum_{j}^{n} \sum_{k}^{n} g_{j k}(i) / g_{j k}}{n^{2}-3 n+2}, j \neq k \neq i, j<k \text {. }
$$

where $i, j$, and $k$ represent stocks, and $g_{j k}$ represents the number of shortcuts between $j$ and $k$. The value range of $B_{i}$ is $[0,1]$. If the betweenness centrality of a stock is 0 , the stock cannot control other stocks and is at the edge of the network. If the betweenness centrality of a stock is 1 , the stock can control $100 \%$ of other stocks, is located at the core of the network, and exerts a considerable influence.

\section{Transmission distance of the stock price fluctuation.}

In the transmission network of the stock price fluctuation of the rare earth industry chain, the transmission distance of the stock price fluctuation refers to the number of intermediate variables that the stock price fluctuation of a stock passes through to other stocks and all stocks in the rare earth industry chain. This indicator describes the speed and efficiency of the transmission of stock price fluctuation of any two stocks. This can be measured as the average shortest path length $L$ of the complex network, the least number of edges that the stocks have to interact with each other, as shown in Equation (9). A smaller $\mathrm{L}$ corresponds to faster transmission of the stock price fluctuation.

$$
\mathrm{L}=\frac{\sum_{\mathrm{i}<\mathrm{j}} \mathrm{d}_{\mathrm{ij}}}{\mathrm{N}(\mathrm{N}-1)}
$$

where $\mathrm{L}$ is the average shortest path length, $\mathrm{N}$ is the number of nodes in the network, $\mathrm{i}$ and $j$ are stocks, and $d_{i j}$ is the number of edges on the shortest path connecting nodes $i$ and $j$. 
4. Transmission cohesion of stock price fluctuation.

The cohesion of the transmission of stock price fluctuation between stocks in the rare earth industry chain refers to the aggregation degree of transmission of stock price fluctuation between stocks, which can be characterized by the clustering coefficient of the nodes. The clustering coefficient of a node refers to the possibility that all nodes connected to the node in the network are also connected to one another. This indicates the stability of the stock's impact on other stocks. The clustering coefficient of node i indicates the possibility that the neighboring nodes of node $i$ are also neighbors of each other, meaning that the number of nodes directly connected to node $i$ is at least 2 . The clustering coefficient of node i can be calculated using Equation (10).

$$
C_{i}=\frac{M_{i}}{k_{i}\left(k_{i}-1\right)}
$$

For a directed network, when node $i$ has $k_{i}$ nodes directly connected to it, $k_{i}\left(k_{i}-1\right)$ represents the maximum possible number of edges between the $k_{i}$ nodes, and $M_{i}$ represents the actual number of edges.

The calculation formula of the average clustering coefficient $C$ is shown in Equation (11).

$$
\mathrm{C}=\frac{1}{\mathrm{~N}} \sum_{\mathrm{i}=1}^{\mathrm{N}} \mathrm{C}_{\mathrm{i}}
$$

5. Transmission path of the stock price fluctuation.

The density table and image matrix between the subgroups obtained by the CONCOR method can be used to study the fluctuation transmission relationship between the subgroups. The value in the density table represents the ratio of the number of edges between the column and row subgroup nodes to the total number of edges. The density of the relationship between any two subgroups in the transmission network of the stock price fluctuation in the rare earth industry chain can be calculated using Equation (12).

$$
\mathrm{D}=\frac{\mathrm{E}_{\alpha \rightarrow \beta}}{\mathrm{P}_{\alpha} \times \mathrm{P}_{\beta}}
$$

where $P_{\alpha}$ and $P_{\beta}$ represent the number of stocks in subgroups $\alpha$ and $\beta$, respectively, and $E_{\alpha \rightarrow \beta}$ represents the number of edges from subgroup $\alpha$ to subgroup $\beta$.

This paper uses the $\alpha$-density index to calculate the value in the image matrix. $\alpha$ is generally the average density value of the network $D_{p}$, and the calculation formula is shown in Equation (13).

$$
\mathrm{D}_{\mathrm{p}}=\frac{\mathrm{E}}{\mathrm{N}(\mathrm{N}-1)}
$$

where $\mathrm{E}$ and $\mathrm{N}$ represent the numbers of network edges and nodes, respectively. If the density $D$ is greater than or equal to the average density value of the network, $D_{p}$, the element in the image matrix is set as 1 ; otherwise, it is set as 0 .

\section{Results and Discussion}

\subsection{Identification of Key Stocks}

3.1.1. Transmission Ability of the Stock Price Fluctuation

By considering the out-degree and in-degree of the nodes in the network, we could identify the transmission ability of the stock price fluctuation and a corresponding degree of influence in the industry chain. Comparing Tables 1 and 2, it can be noted that except for 8058.T (Japan), stocks with a strong transmission ability in the whole industrial chain also have a strong transmission ability in their own links. Except 600580.SH (China) and BFA.L (Germany), the remaining stocks which are strongly affected by the price fluctuation of other stocks in the whole industrial chain are greatly affected by the price fluctuation of 
other stocks in their own links. This finding indicates that fluctuation in the stock price of the entire rare earth industry on the chain is highly correlated. Moreover, such stocks must be emphasized in their links and in the whole rare earth industry chain.

Table 1. Transmission capacity and influence degree of stock price fluctuation in each link of the rare earth industry chain (top5).

\begin{tabular}{|c|c|c|c|c|c|c|}
\hline Sub-Network & Stock Code & Country & Transmission Capacity & Stock Code & Country & Influence Degree \\
\hline \multirow{5}{*}{ upstream } & AVL.TO & Canada & 6 & AVL.TO & Canada & 5 \\
\hline & 600549.SH & China & 4 & 600111.SH & China & 3 \\
\hline & 601600.SH & China & 2 & 600259.SH & China & 2 \\
\hline & 600111.SH & China & 1 & 000831.SZ & China & 2 \\
\hline & 600259.SH & China & 1 & 600549.SH & China & 1 \\
\hline \multirow{5}{*}{ midstream } & 600549.SH & China & 17 & ALB.N & U.S & 19 \\
\hline & BFA.L & Germany & 10 & GE.N & U.S & 16 \\
\hline & 5486.T & Japan & 8 & PHG.N & Holland & 15 \\
\hline & 4004.T & Japan & 8 & JMAT.L & U.K. & 12 \\
\hline & 4188. T & Japan & 7 & UMI.BR & Belgium & 8 \\
\hline \multirow{5}{*}{ downstream } & 002249.SZ & China & 19 & F.N & U.S & 14 \\
\hline & BFA.L & Germany & 9 & ALB.N & U.S & 14 \\
\hline & 6954.T & Japan & 7 & JMAT.L & U.K & 13 \\
\hline & 6503.T & Japan & 6 & ABB.N & Switzerland & 13 \\
\hline & 6506.T & Japan & 6 & UMI.BR & Belgium & 8 \\
\hline
\end{tabular}

Table 2. Transmission capacity and influence degree of stock price fluctuation in the whole rare earth industry chain (top10).

\begin{tabular}{|c|c|c|c|c|c|}
\hline Stock Code & Country & Transmission Capacity & Stock Code & Country & Influence Degree \\
\hline AVL.TO & Canada & 43 & ALB.N & U.S. & 34 \\
\hline 002249.SZ & China & 43 & F.N & U.S. & 32 \\
\hline 600549.SH & China & 35 & ABB.N & Switzerland & 30 \\
\hline BFA.L & Germany & 16 & GE.N & U.S. & 27 \\
\hline 601600.SH & China & 11 & JMAT.L & U.K. & 26 \\
\hline 8058.T & Japan & 11 & PHG.N & Holland & 26 \\
\hline 5486.T & Japan & 10 & AVL.TO & Canada & 16 \\
\hline 4004.T & Japan & 10 & UMI.BR & Belgium & 16 \\
\hline 6954.T & Japan & 10 & 600580.SH & China & 15 \\
\hline 4188.T & Japan & 10 & BFA.L & Germany & 12 \\
\hline
\end{tabular}

The most critical stocks are AVL.TO (Canada) and 002249.SZ (China). The price fluctuations of these two stocks will cause the price fluctuations of 43 other stocks in the industry chain except themselves. The former stock can transmit price fluctuation to the other 6 stocks in the upstream link, and the latter stock can transmit price fluctuation to the other 19 stocks in the downstream link. In other words, the fluctuation in the price of these two stocks may lead to a notable fluctuation in the price of any other stock in the whole industrial chain. Among the 7 stocks occupying two links in the industrial chain, 600549.SH (China) has a strong transmission ability in the upstream, midstream, and the whole industrial chain. In addition, BFA.L (Germany) has strong transmission capabilities in the midstream, downstream, and the whole industrial chain. However, ALB.N (U.S.) is strongly affected by other stock price volatilities in the midstream, downstream, and the whole industrial chain. In other words, the stock is relatively fragile and must enhance its ability to prevent and control the risk of stock price fluctuation.

Three of the top five stocks in the overall industry chain are Chinese companies. It can be seen that the transmission of Chinese companies in the upper reaches of the industry chain occupies an important position. This is because, for a long time, China has occupied the world's largest rare earth reserves and has assumed the role of the world's major rare earth supplier. In the top 10 stocks, 5 stocks are from Japan, indicating that Japanese companies occupy an important position in the middle and lower reaches. As Japanese 
companies mostly use rare earths in polishing materials, magnets, batteries, and ceramics, and the products they produce, such as large-screen TVs, automobiles, and small motors, they are increasingly indispensable for daily production. This has made Japan a major consumer of rare earths and therefore Japan occupies an important position in the rare earth industry chain.

It can be seen from Figure 4, with the exception of the upstream links of the industrial chain, $1 / 5$ of the stocks in the remaining links and the entire industrial chain have suffered about half of the stock price fluctuation. Indicating that the network is relatively stable and the stocks that are susceptible to fluctuation are relatively few. The transmission capacity of the seven stocks in the upstream link does not have similar characteristics as other links. This is because, on the one hand, there are fewer stocks in the upstream link. On the other hand, the upstream companies are mainly responsible for the development of rare earth mines. The production is mainly based on the output of its own deposits, and it is less affected by each other.

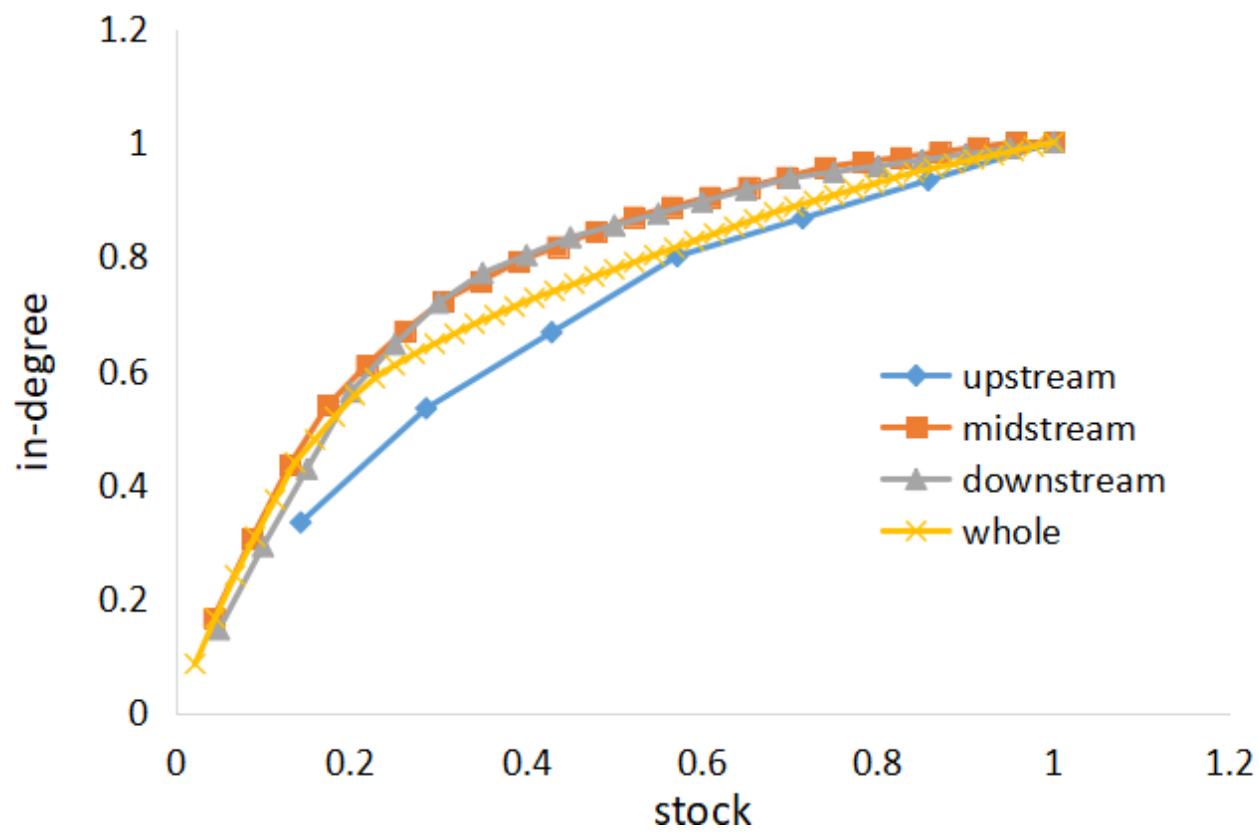

Figure 4. Cumulative distributions of in-degree of each network.

\subsubsection{Capacity of Transmission Media of the Stock Price Fluctuation}

Stocks with a strong transmission ability play key roles as media. Identifying the transmission media ability of stocks can help identify the transmission path of the stock price fluctuation. Tables 3 and 4 list the five stocks that exhibit the highest transmission control power of stock price fluctuation in each link of the rare earth industry chain and the ten stocks that exhibit the highest transmission control power of stock price fluctuation in the whole industry chain. AVL.TO (Canada) has the highest transmission media capacity in the upstream links and the whole industrial chain. BFA.L (Germany) has a considerably higher price transmission control power than other stocks in the midstream and downstream links. BFA.L (Germany) is a large international chemical company that produces various products in 39 countries and has business dealings with customers in more than 170 countries. Many stocks in the rare earth industry chain are directly connected to it or through it to other stocks. In combination with the analysis of the transmission capacity, it can be noted that these stocks significantly influence the price fluctuation transmission path of the stock price fluctuation in the rare earth industry chain. Controlling the price fluctuation of these stocks can help ensure the stability of stock prices in all links of the whole industrial chain. 
Table 3. Transmission medium capacity of stock price fluctuation in each link of the rare earth industry chain (top 5).

\begin{tabular}{|c|c|c|c|c|}
\hline Sub-Network & Stock Code & Country & Out-Degree & Betweenness Centrality \\
\hline \multirow{5}{*}{ upstream } & AVL.TO & Canada & 6 & 0.7000 \\
\hline & 600111.SH & China & 1 & 0.0000 \\
\hline & 600259.SH & China & 1 & 0.0000 \\
\hline & 000831.SZ & China & 0 & 0.0000 \\
\hline & 600549.SH & China & 4 & 0.0000 \\
\hline \multirow{5}{*}{ midstream } & BFA.L & Germany & 10 & 0.2165 \\
\hline & GE.N & U.S. & 2 & 0.1203 \\
\hline & 6502.T & Japan & 3 & 0.1160 \\
\hline & PHG.N & Holland & 4 & 0.1074 \\
\hline & JMAT.L & U.K. & 5 & 0.0994 \\
\hline \multirow{5}{*}{ downstream } & BFA.L & Germany & 9 & 0.2221 \\
\hline & 002249.SZ & China & 19 & 0.1535 \\
\hline & 6954.T & Japan & 7 & 0.1473 \\
\hline & JMAT.L & U.K. & 4 & 0.0605 \\
\hline & 002196.SZ & China & 3 & 0.0432 \\
\hline
\end{tabular}

Table 4. Transmission medium capacity of stock price fluctuation in the whole rare earth industry chain(top10).

\begin{tabular}{cccc}
\hline Stock Code & Country & Out-Degree & Betweenness Centrality \\
\hline AVL.TO & Canada & 43 & 0.4048 \\
JMAT.L & U.K. & 8 & 0.1881 \\
4188.T & Japan & 10 & 0.1542 \\
GE.N & U.S. & 3 & 0.0985 \\
600366.SH & China & 9 & 0.0849 \\
BFA.L & Germany & 16 & 0.0814 \\
6502.T & Japan & 5 & 0.0519 \\
ABB.N & Switzerland & 2 & 0.0468 \\
PHG.N & Holland & 6 & 0.0344 \\
600549.SH & China & 35 & 0.0281 \\
\hline
\end{tabular}

Although some stocks do not have a high transmission capacity, they have a strong intermediary capacity because they are connected to many key stocks. For example, GE.N (United States) receives the fluctuation transmission of key stocks such as stocks AVL.TO (Canada) and 002249.SZ (China), and subsequently acts as an intermediary to pass the fluctuation to other connected stocks. Therefore, it becomes a stock with a key media role and plays an important role in the industrial chain.

\subsubsection{Transmission Cohesion of the Stock Price Fluctuation}

The clustering coefficient of a node quantifies the cohesion of price fluctuation transmission between a stock and its related stocks. A higher clustering coefficient of a node corresponds to a stronger transmission relationship between the stock and the related stocks. Moreover, this coefficient indicates that the price fluctuation transmission relationship between the stock and the related stocks is relatively weak, and the possibility of price fluctuation transmission to other stocks is large. Table 5 shows that the overall transmission cohesion of stocks upstream of the industrial chain is higher than those of the midstream and downstream links, indicating that the transmission relationship generated by stock price fluctuation in the upstream links is relatively stable and Chinese listed companies occupy an important position.

Moreover, Table 6 shows that the transmission capacity of stocks with a higher transmission cohesion in the whole industry chain and the degree of influence of other stock price volatilities are not high. However, the fluctuation of these stock prices affects the other stocks within a certain range, thereby increasing the risk of market fluctuation. Therefore, stocks with high clustering coefficients must be monitored to implement effective measures in time to prevent drastic market fluctuation. 
Table 5. Transmission cohesion of stock price fluctuation in each link of the rare earth industry chain (top 5).

\begin{tabular}{ccccc}
\hline Sub-Network & Stock Code & Country & Out-Degree & Clustering \\
\hline \multirow{5}{*}{ upstream } & $600259 . \mathrm{SH}$ & China & 1 & 1.0000 \\
& $000831 . \mathrm{SZ}$ & China & 0 & 1.0000 \\
& $601600 . \mathrm{SH}$ & China & 2 & 1.0000 \\
& $600111 . \mathrm{SH}$ & China & 1 & 0.6667 \\
& $600549 . \mathrm{SH}$ & China & 4 & 0.4167 \\
\hline \multirow{5}{*}{ midstream } & $600206 . \mathrm{SH}$ & China & 3 & 0.4167 \\
& $4183 . \mathrm{T}$ & Japan & 3 & 0.4167 \\
& $6502 . \mathrm{T}$ & Japan & 3 & 0.4048 \\
& $600366 . \mathrm{SH}$ & China & 4 & 0.4048 \\
& $000969 . \mathrm{SZ}$ & China & 4 & 0.4000 \\
\hline \multirow{5}{*}{ downstream } & $0179 . \mathrm{HK}$ & Bermuda & 4 & 0.5000 \\
& $300032 . \mathrm{SZ}$ & China & 2 & 0.5000 \\
& $7203 . \mathrm{T}$ & Japan & 5 & 0.4286 \\
& $600459 . \mathrm{SH}$ & China & 5 & 0.4000 \\
& $6506 . \mathrm{T}$ & Japan & 6 & 0.3900 \\
\hline
\end{tabular}

Table 6. Transmission cohesion of stock price fluctuation in the whole rare earth industry chain(top 10).

\begin{tabular}{cccc}
\hline Stock Code & Country & Out-Degree & Clustering \\
\hline 300127.SZ & China & 0 & 0.6667 \\
002196.SZ & China & 4 & 0.4722 \\
005930.KS & Korea & 6 & 0.4722 \\
0179.HK & Bermuda & 5 & 0.4583 \\
LYC.AX & Australia & 6 & 0.4464 \\
600259.SH & China & 6 & 0.4444 \\
000970.SZ & China & 8 & 0.4444 \\
7203.T & Japan & 8 & 0.4394 \\
6502.T & Japan & 5 & 0.4364 \\
4183.T & Japan & 6 & 0.4306 \\
\hline
\end{tabular}

\subsubsection{Transmission Distance of the Stock Price Fluctuation}

According to the operating results of each network, the relevant index values of the stock price fluctuation transmission distance of each link in the rare earth industry chain can be obtained as shown in Table 7. Considering the whole network as an example, it can be concluded that the diameter of the transmission network of the stock price fluctuation in the whole rare earth industry chain is 6 . This finding shows that the stock price fluctuation of any one of the 44 stocks can affect the stock prices of other stocks through up to 5 stocks as the media. The average shortest path of the network is 2.367 , indicating that the distance and speed of the stock price fluctuation among different stocks are low. The average shortest paths of the upstream, midstream, and downstream sub-networks are 1.583, 2.329 , and 2.096, respectively, all of which correspond to a relatively small transmission distance of the stock price fluctuation. The clustering coefficients are $0.602,0.303$, and 0.346 . The upstream network density is high, and the relationship between the stocks is strong. Moreover, the small average shortest path upstream (1.583) and large clustering coefficient (0.602) indicate that the transmission network of the stock price fluctuation upstream of the rare earth industry chain involves notable small-world characteristics.

Table 7. Related indicators of transmission distance of stock price fluctuation in each link of the rare earth industry chain.

\begin{tabular}{cccc}
\hline Network & Network Diameter & Average Clustering Coefficient & Average Path Length \\
\hline upstream & 2 & 0.602 & 1.583 \\
midstream & 6 & 0.303 & 2.329 \\
downstream & 5 & 0.346 & 2.096 \\
whole & 6 & 0.364 & 2.367 \\
\hline
\end{tabular}




\subsection{Transmission Path of the Stock Price Fluctuation}

\subsubsection{Transmission Path Based on CONCOR Method}

The transmission path analysis of the stock price fluctuation can effectively identify the transmission mechanism among the links of the rare earth industry chain and narrow the scope of the stock price fluctuation risk detection. According to the network of the whole rare earth industry chain, 6502.T is the complete receiver of price fluctuation. It is a separate division under any divisional conditions, which affects the overall divisional results of individual stocks in the entire industry chain. This article deletes the stock and partitions the remaining stocks. When we use the CONCOR method to set the segmentation depth to 3, 8 subgroups are obtained. Due to the small number of stocks, the number of stocks contained in some subgroups is only 1 , and the partitioning effect is poor. When the segmentation depth is set to 2, a good partition result is obtained. We modularize the overall network of stock price fluctuation in the rare earth industry chain to obtain the optimal subgroup division result, block matrix, and density matrix. The network is divided into 4 subgroups. The block matrix shows the number of edges between members of each subgroup, as indicated in Table 8.

Table 8. The stock composition of each module of the whole industrial chain network.

\begin{tabular}{|c|c|c|c|}
\hline Subgroup & Members of the Subgroup & Node Number & Edge Number \\
\hline 1 & $\begin{array}{c}\text { 601600.SH, 600111.SH, 4188.T, 6762.T, 600259.SH, LYC.AX, } \\
\text { 4004.T, 600366.SH, 000970.SZ, 300127.SZ, 000969.SZ, 6971.T, } \\
\text { 5486.T, 600459.SH, 4063.T, BFA.L, 002176.SZ, 600206.SH, } \\
\text { 6503.T, 7203.T, 8058.T, 6752.T, 002196.SZ, 005930.KS, 4183.T, } \\
\text { 6506.T, 0179.HK, 6954.T, 7267.T }\end{array}$ & 29 & 41 \\
\hline 2 & $\begin{array}{c}\text { 300032.SZ, 600549.SH, 000831.SZ, 300124.SZ, } \\
\text { AVL.TO, 002249.SZ }\end{array}$ & 6 & 19 \\
\hline 3 & UMI.BR, PHG.N, ABB.N, JMAT.L & 4 & 4 \\
\hline 4 & GE.N, 600580.SH, ALB.N, F.N & 4 & 1 \\
\hline
\end{tabular}

In this network, the stock price fluctuation of different subgroups affects those of other subgroups, and the stock price fluctuation of one subgroup is transmitted to other subgroups. The fluctuation transmission ability of subgroups can be expressed as the sum of the out-degrees of the members of the subgroups. The fluctuation transmission ability within and between subgroups are shown in Figures 5 and 6 . A deeper yellow corresponds to fewer relationships, and a deeper red corresponds to more relationships. According to Figures 5 and 6 , it can be noted that the Granger causality relationship within the four subgroups is 385 , and the number of fluctuation transmission relationships between the four subgroups is 320 . In other words, the transmission effect of the stock price fluctuation between the subgroups is notable. Subgroups 1 and 2 contain 29 stocks and 6 stocks, respectively, and the numbers of other affected subgroups are 185 and 119, accounting for $57.81 \%$ and $37.19 \%$, respectively. Therefore, subgroups 1 and 2 belong to the stock subgroup with a strong transmission ability of the stock price fluctuation. Subgroups 3 and 4 contain 4 stocks each, and the numbers of stocks affected by other subgroups are 93 and 107 , accounting for $29.06 \%$ and $33.44 \%$, respectively. Therefore, subgroups 3 and 4 belong to the stock subgroup that is greatly affected by the fluctuation of other stocks. According to Figure 7, which shows the relationship density between the four subgroups, the causality density of subgroup 1 to subgroup 4 is the largest, with a value of 0.733 . Therefore, the causality transmission from subgroup 1 to subgroup 4 is the most significant. Subgroup 2 has a high density of causality to other subgroups as a whole, indicating that the transmission of stock price fluctuation from subgroup 2 is relatively stable. 


\begin{tabular}{|c|c|c|c|c|c|c|}
\hline subgroup & 1 & 2 & 3 & 4 & total & proportion \\
\hline 1 & 41 & 21 & 79 & 85 & 226 & $58.70 \%$ \\
\hline 2 & 91 & 19 & 12 & 16 & 138 & $35.84 \%$ \\
\hline 3 & 6 & 0 & 4 & 6 & 16 & $4.16 \%$ \\
\hline 4 & 2 & 0 & 2 & 1 & 5 & $1.30 \%$ \\
\hline total & 140 & 40 & 97 & 108 & 385 & $100 \%$ \\
\hline proportion & $36.36 \%$ & $10.39 \%$ & $25.19 \%$ & $28.05 \%$ & $100 \%$ & \\
\hline
\end{tabular}

Figure 5. The number of Granger causality within and between subgroups.

\begin{tabular}{|c|c|c|c|c|c|c|}
\hline subgroup & 1 & 2 & 3 & 4 & total & proportion \\
\hline 1 & 0 & 21 & 79 & 85 & 185 & $57.81 \%$ \\
\hline 2 & 91 & 0 & 12 & 16 & 119 & $37.19 \%$ \\
\hline 3 & 6 & 0 & 0 & 6 & 12 & $3.75 \%$ \\
\hline 4 & 2 & 0 & 2 & 0 & 4 & $1.25 \%$ \\
\hline total & 99 & 21 & 93 & 107 & 320 & $100.00 \%$ \\
\hline proportion & $30.94 \%$ & $6.56 \%$ & $29.06 \%$ & $33.44 \%$ & $100 \%$ & \\
\hline
\end{tabular}

Figure 6. The number of Granger causality between subgroups. 


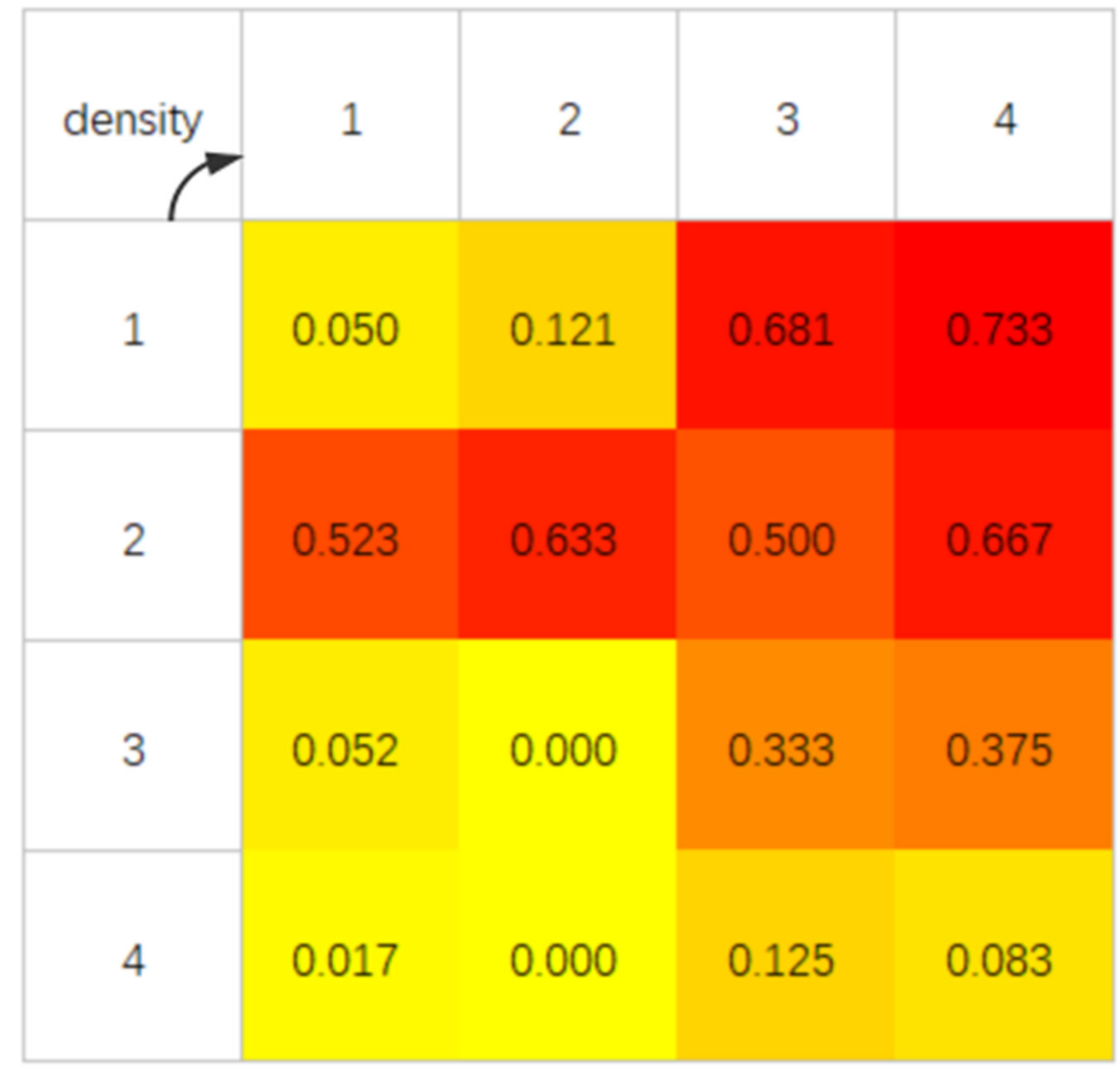

Figure 7. Granger causality density between subgroups.

The average density of the stock price fluctuation network of the rare earth industry chain is 0.393 . In combination with the density matrix shown in Figure 6, we could obtain an image matrix, as shown in Figure 8. According to the diagonal of the image matrix, the value of subgroup 2 is 1 , which indicates that the fluctuation transmission path within this subgroup is highly important compared to other subgroups. According to Figure 8, the transmission path between subgroups is extracted and schematically illustrated in Figure 9 . Subgroup 1 is both the sender and the receiver of fluctuation transmission and plays a clear mediating role in the whole network. Subgroup 2 is the sender of wave conduction and only receives self-transmission. Subgroups 3 and 4 are fluctuation transmission receivers. These findings indicate that the Granger causality between the stock prices of the rare earth industry chain, that is, the transmission relationship of the stock price fluctuation, is mainly transmitted from subgroup 2 to subgroup 1 and further to subgroups 3 and 4 , or directly transmitted from subgroup 1 to subgroup 3 , or transmitted from subgroup 2 to subgroup 4 directly.

According to Table 8 and Figure 9, the transmission path of the stock price fluctuation in the rare earth industry chain is overlaid on the transmission path of the stock price fluctuation in the rare earth industry chain which includes 6502.T, as shown in Figure 10. The stocks in any of the upstream, midstream and downstream links can play any role in the transmission path. The fluctuation transmission primarily originates from the stocks upstream and midstream; the stocks with an intermediary role are mainly in the midstream and downstream links; and the recipients of the wave transmission are stocks in the midstream and downstream links. 


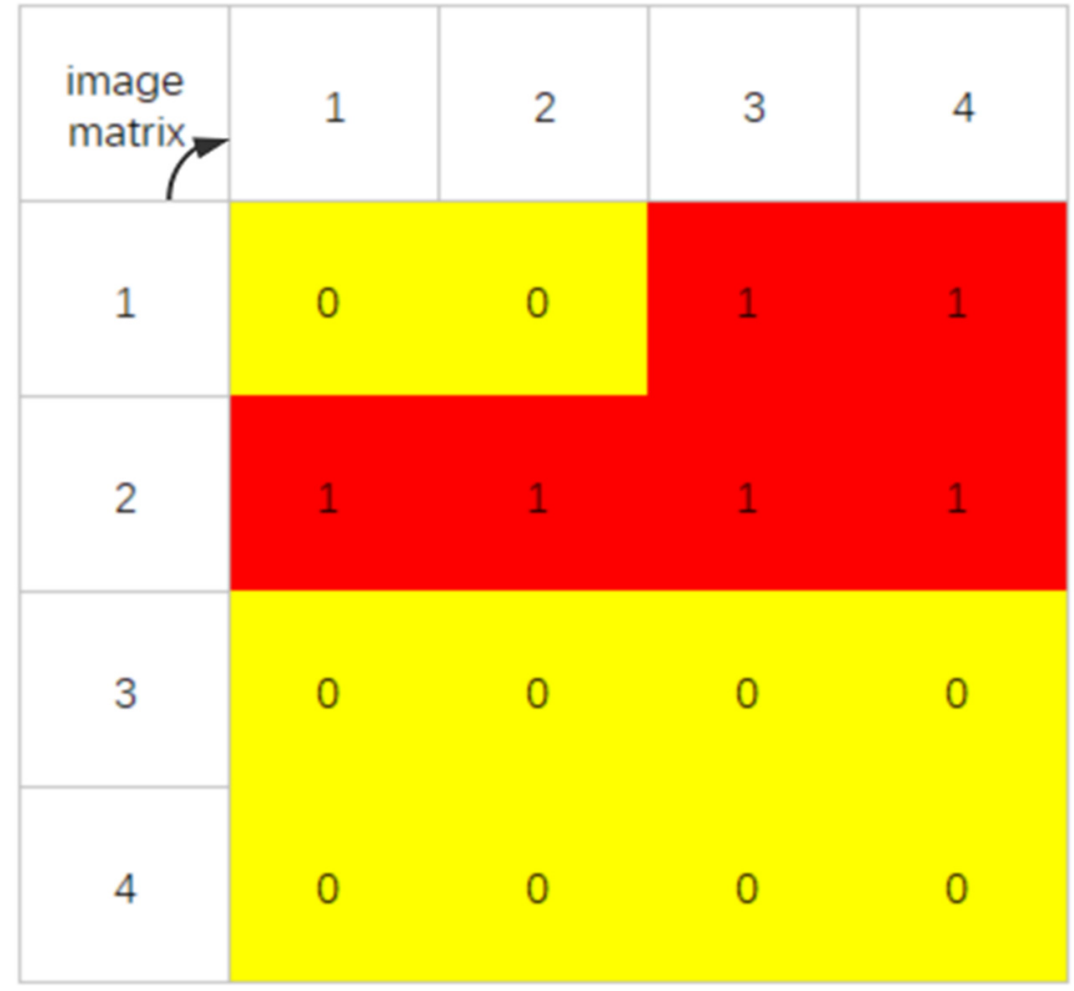

Figure 8. Image matrix between subgroups.

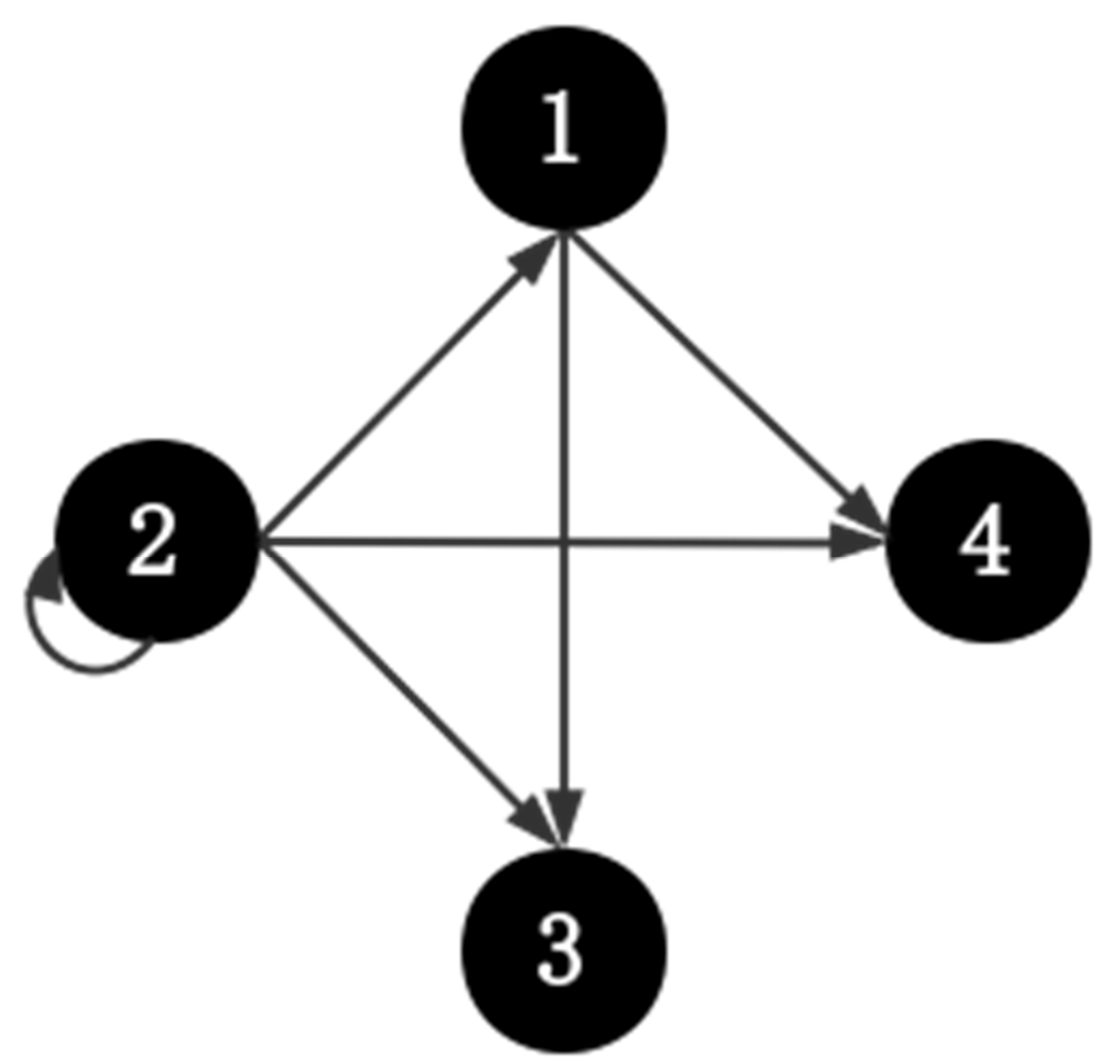

Figure 9. Transmission path between subgroups. 


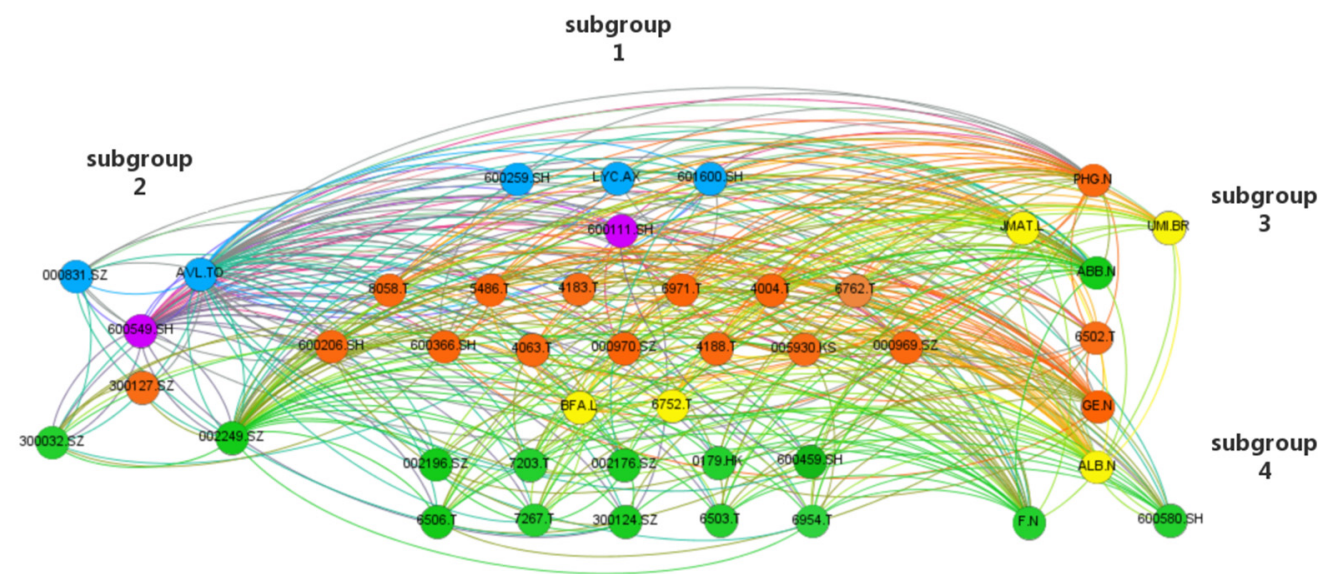

Figure 10. The transmission path of stock price fluctuation of the rare earth industry chain.

Based on the identification results of the above key nodes and the division of fluctuation transmission roles, after removing the relationship between the internal stocks of the links, the critical paths between the various links of the industrial chain as shown in Figure 11 are identified. Among them, there has also been a wave transmission from the middle to the upstream, such as 4188.T to AVL.TO and 600366.SH to AVL.TO. It shows that the transmission of volatility from the midstream to the upstream is also an important transmission mechanism. The midstream link obtains rare earth mineral raw materials from the upstream link. When the midstream demand changes, the upstream supply will change accordingly, which causes the stock price fluctuations in the upstream link.
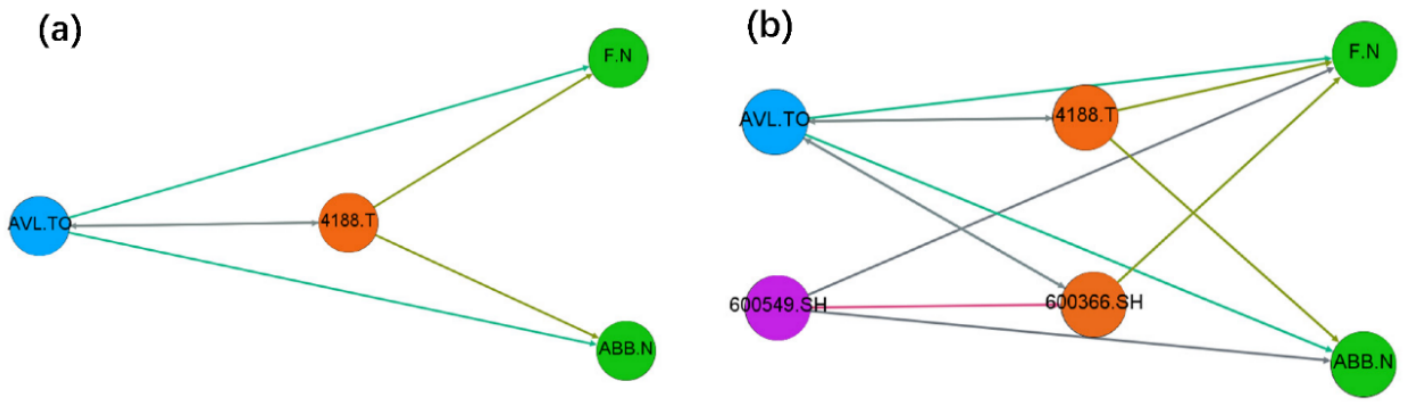

(c)

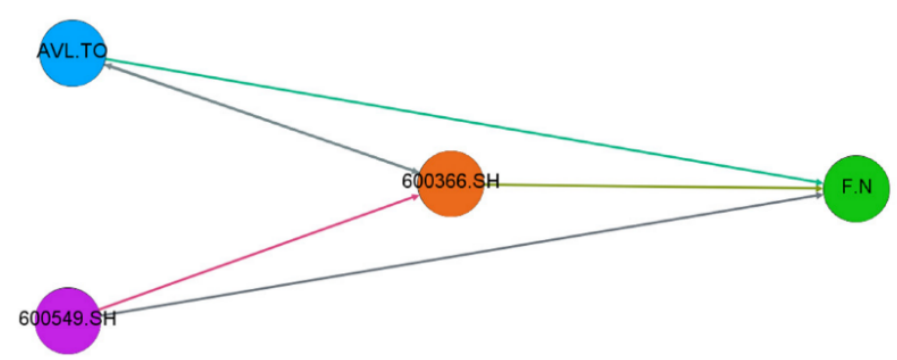

Figure 11. The critical path between each link in the rare earth industry chain.

\subsubsection{Transmission Path Based on Maximum Spanning Tree}

Figure 12 shows the largest spanning tree of the stock price fluctuation network of the rare earth industry chain, and its analysis program is written by Matlab software. The graph reflects the shortest path through which stock price fluctuation are transmitted to the entire network. As can be seen from the graph, 601600.SH (China), AVL.TO (Canada) and 600549.SH (China) are the central nodes, and three major clusters are formed through the clustering effect. The fluctuation sender cluster is centered on 601600.SH (China), the intermediary cluster centered on AVL.TO (Canada), and the fluctuation receiver cluster centered on 600549.SH (China). Among them, the clustering effect of fluctuation receivers 
is the most significant. Chinese stocks are at the center of the network, indicating that China plays a key role in the network of stock price fluctuation in the rare earth industry chain. At the same time, combined with the direction of transmission, it can be seen that the stock price fluctuation is generally sent from the upper and midstream links to the midstream and downstream links, which is the same as the overall transmission path identified by the CONCOR method.

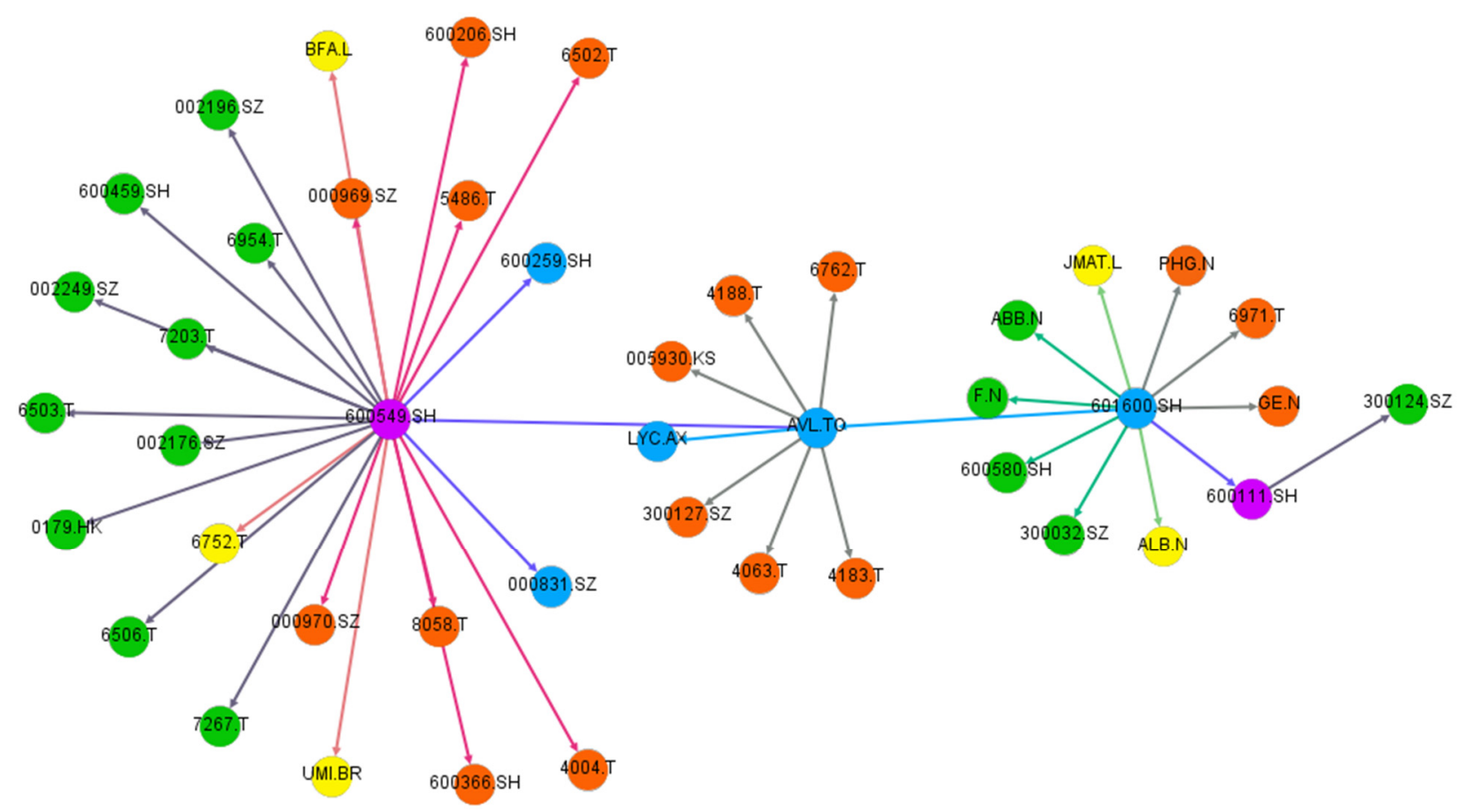

Figure 12. The largest spanning tree of the stock price fluctuation network of the rare earth industry chain.

\section{Conclusions}

At present, research on the rare earth industry chain and rare earth stock market is relatively separate. Most of the existing studies focus on the spillover effect of stock price fluctuation between the rare earth stock market and other stock markets and examine the mutual influence of the investment risks among different markets. Compared with that on the rare earth market investment risk, research on the stock market of the rare earth industry chain is limited. Considering this aspect, this article uses the Granger causality test and complex network theory to construct a transmission network of the stock price fluctuation in the rare earth industry chain. The transmission ability and transmission path characteristics of each stock in the rare earth industry chain are discussed. The objectives are to enrich the rare earth industry chain stock price fluctuation transmission theory and provide a reference for market participants in the rare earth industry chain to prevent and control market fluctuation risks. The following conclusions are derived:

(1) According to the CONCOR method and the maximum spanning tree model to identify the conduction path. As a whole, the transmission of stock price fluctuations in the rare earth industry chain is mainly based on the upstream and midstream links as the starting point of the fluctuations, and then affects the stock prices of midstream and downstream companies. At the same time, it also contains the adverse effects from the midstream to the upstream. Therefore, from the perspective of stabilizing stock prices and safeguarding shareholders' rights, midstream and downstream listed companies should pay attention to the stock price fluctuations of upstream and midstream companies, especially AVL.TO (Canada) and 600549.SH (China). Upstream listed companies should pay attention to the stock price fluctuations of midstream listed companies in a timely manner, and take early measures to avoid the impact of abnormal stock price fluctuations in midstream and upstream companies. At the same 
time, all listed companies should actively pay attention to the abnormal fluctuations of 4188.T (Japan) and 600366.SH (China), which mainly play an intermediary role in the midstream link.

(2) According to the key stock identification results and the central node identification results of the largest spanning tree: 601600.SH (China), AVL.TO (Canada) and 600549.SH (China), play key role in the stock price fluctuation network of the rare earth industry chain. When investors are trading stocks, they could focus on the fluctuation of these stocks and make trading judgments in advance.

(3) China as a major rare earth supplier, and Japan as a major rare earth consumer, both play an important role in the transmission of stock price fluctuation in the rare earth industry chain. Regulators must conduct regular information statistics and financial evaluations for these influential companies, maintain the stability of the rare earth stock market, and prevent the spread of risks.

(4) The transmission distance of the stock price fluctuation in each network is small. The rise and fall of one stock is expected to affect other stocks in this distance. All market participants should focus on the fluctuation of the stock prices in the rare earth market and the fluctuation of the stock prices of companies that are significantly related to the fluctuation of their own stock prices. When abnormal conditions are detected, the investment intensity should be adjusted in time, the market investment strategy should be changed, and the investment risk should be effectively reduced.

Author Contributions: Conceptualization, Methodology, Investigation, Writing-Original Draft Preparation, Writing-Review and Editing, Y.J.; Visualization, Supervision, Project Administration, Funding Acquisition, C.D.; Methodology, Software, Z.D. All authors have read and agreed to the published version of the manuscript.

Funding: The National Social Science Foundation of China (Grant No. 17BGL202).

Institutional Review Board Statement: Not applicable.

Informed Consent Statement: Not applicable.

Data Availability Statement: The data presented in this study are openly available at wind database (accessed on 4 August 2021).

Conflicts of Interest: The authors declare no conflict of interest.

\section{References}

1. Xia, C.B.; Wen-Jun, G.E.; Wang, D.J.; Chen, M.H. Application of Rare Earth Elements in Military. Dev. Innov. Mach. Electr. Prod. 2010, 6. [CrossRef]

2. Houssay, E.; Rouault, A.; Thomas, O.; Madar, R.; Senateur, J.P. Metallurgical reinvestigation of rare earth silicides. Appl. Surf. Sci. 1989, 38, 156-161. [CrossRef]

3. Liu, B.; Zhang, F.; Ma, X.; Petrochemical, C.S.; Petroleum, L.C. Research and Development of Rare Earth Catalyst for Synthesis of Cis-polybutadiene Rubber. Mod. Chem. Res. 2018, 2, 467-492.

4. Dutta, T.; Kim, K.H.; Uchimiya, M.; Kwon, E.E.; Jeon, B.H.; Deep, A.; Yun, S.T. Global demand for rare earth resources and strategies for green mining. Environ. Res. 2016, 150, 182-190. [CrossRef] [PubMed]

5. $\mathrm{Xu}, \mathrm{F}$; $\mathrm{Li}, \mathrm{H}$; $\mathrm{Li}, \mathrm{Y}$. Ecological environment quality evaluation and evolution analysis of a rare earth mining area under different disturbance conditions. Environ. Geochem. Health 2020, 43, 2243-2256. [CrossRef] [PubMed]

6. Rim, K.T.; Koo, K.H.; Park, J.S. Toxicological Evaluations of Rare Earths and Their Health Impacts to Workers: A Literature Review. Saf. Health Work 2013, 4, 12-26. [CrossRef] [PubMed]

7. Wübbeke, J. Rare earth elements in China: Policies and narratives of reinventing an industry. Resour. Policy 2013, 38, 384-394. [CrossRef]

8. Hayes-Labruto, L.; Schillebeeckx, S.; Workman, M.; Shah, N. Contrasting perspectives on China's rare earths policies: Reframing the debate through a stakeholder lens. Energy Policy 2013, 63, 55-68. [CrossRef]

9. Brown, M.; Eggert, R. Simulating producer responses to selected chinese rare earth policies. Resour. Policy 2018, 55, 31-48. [CrossRef]

10. Mei, H.; Hao, F. A Study on the Real Estate Price Forecast Model in the Midwest of China-Based on Provincial Panel Data Analysis; Springer: Singapore, 2017.

11. Wang, J.; Guo, M.; Liu, M.; Wei, X. Long-term outlook for global rare earth production. Resour. Policy 2020, 65, 101569. [CrossRef] 
12. Rollat, A.; Guyonnet, D.; Planchon, M.; Tuduri, J. Prospective analysis of the flows of certain rare earths in Europe at the 2020 horizon. Waste Manag. 2016, 49, 427-436. [CrossRef]

13. Kahn, A.E. Investment Criteria in Development Programs. Q. J. Econ. 1951, 65, 38-61. [CrossRef]

14. Porter, M.E. Technology and competitive advantage. J. Bus. Strategy 1985, 5, 60-78. [CrossRef]

15. Stevens, G.C. Integrating the Supply Chain. Int. J. Phys. Distrib. Logist. Manag. 1989, 19, 3-8. [CrossRef]

16. Carlo, P.; Anabel, M.; Jocelyn, O. Innovation in mining value chains: New evidence from Latin America. Resour. Policy 2018, 58, 1-10.

17. Zhang, B.; Bai, S.; Ning, Y.; Ding, T.; Zhang, Y. Emission Embodied in International Trade and Its Responsibility from the Perspective of Global Value Chain: Progress, Trends, and Challenges. Sustainability 2020, 12, 3097. [CrossRef]

18. Shao, L.; Jin, S. Resilience assessment of the lithium supply chain in China under impact of new energy vehicles and supply interruption. J. Clean. Prod. 2019, 252, 119624. [CrossRef]

19. Meng, B.; Xue, J.; Feng, K.; Guan, D. China's inter-regional spillover of carbon emissions and domestic supply chains. IDE Discuss. Pap. 2012, 61, 1305-1321. [CrossRef]

20. Wang, X.; Lei, Y.; Ge, J.; Wu, S. Production forecast of Chinas rare earths based on the Generalized Weng model and policy recommendations. Resour. Policy 2015, 43, 11-18. [CrossRef]

21. Ge, J.; Lei, Y.; Zhao, L. China's Rare Earths Supply Forecast in 2025: A Dynamic Computable General Equilibrium Analysis. Minerals 2016, 6, 95. [CrossRef]

22. Wang, X.; Yao, M.; Li, J.; Zhang, K.; Zheng, M. China's Rare Earths Production Forecasting and Sustainable Development Policy Implications. Sustainability 2017, 9, 1003. [CrossRef]

23. Samsonov, N.Y. Global Chains of Supply of Rare-Earth and Rare Metals as High-Tech Raw Materials within the Framework of International Industrial Cooperation. Spat. Econ. 2018. [CrossRef]

24. Jiangxia; Liu; Sourish; Sarkar; Sanjay; Kumar; Zhenhu; Jin, An analysis of stock market impact from supply chain disruptions in Japan. Int. J. Product. Perform. Manag. 2018, 67, 192-206. [CrossRef]

25. Wang, Y. The Fourth Transformations of Stock Administration-Supply Chain Management. Logist. Manag. 2004, 150, 107-127.

26. Reboredo, J.C.; Ugolini, A. Price spillovers between rare earth stocks and financial markets. Resour. Policy 2020, 66, 101647. [CrossRef]

27. Chen, Y.; Zheng, B.; Qu, F.; Eggert, R.G. Modeling the nexus of crude oil, new energy and rare earth in China: An asymmetric VAR-BEKK (DCC)-GARCH approach. Resour. Policy 2020, 65, 101545. [CrossRef]

28. Bouri, E.; Kanjilal, K.; Ghosh, S.; Roubaud, D.; Saeed, T. Rare earth and allied sectors in stock markets: Extreme dependence of return and volatility. Appl. Econ. 2021, 53, 5710-5730. [CrossRef]

29. Zheng, B.; Zhang, Y.; Chen, Y. Asymmetric connectedness and dynamic spillovers between renewable energy and rare earth markets in China: Evidence from firms' high-frequency data. Resour. Policy 2021, 71, 101996. [CrossRef]

30. Liu, S.; Dong, Z.; Ding, C.; Wang, T.; Zhang, Y. Do you need cobalt ore? Estimating potential trade relations through link prediction. Resour. Policy 2020, 66, 101632. [CrossRef]

31. Wang, M.; Chen, Y.; Tian, L.; Jiang, S.; Tian, Z.; Du, R. Fluctuation behavior analysis of international crude oil and gasoline price based on complex network perspective. Appl. Energy 2016, 175, 109-127. [CrossRef]

32. Dong, Z.; An, H.; Liu, S.; Li, Z.; Yuan, M. Research on the time-varying network structure evolution of the stock indices of the BRICS countries based on fluctuation correlation. Int. Rev. Econ. Financ. 2020, 69, 63-74. [CrossRef]

33. He, Z.; Xiao, L.; Guo, Q.; Liu, Y.; Kareiva, P. Evidence of Causality between Economic Growth and Vegetation Dynamics and Implications for Sustainability Policy in Chinese Cities. J. Clean. Prod. 2019, 251, 119550. [CrossRef]

34. Lu, W.C. Electricity Consumption and Economic Growth: Evidence from 17 Taiwanese Industries. Sustainability 2016, 9, 50. [CrossRef]

35. Cheng, H.; Wang, Y.; Wang, Y.; Yang, T. Inferring Causal Interactions in Financial Markets Using Conditional Granger Causality Based on Quantile Regression. Comput. Econ. 2021. [CrossRef]

36. Algieri, B.; Brancaccio, E.; Buonaguidi, D. Stock market volatility, speculation and unemployment: A Granger-causality analysis. PSL Q. Rev. 2020, 73, 137.

37. Sun, Q.; Gao, X.; Wen, S.; Chen, Z.; Hao, X. The transmission of fluctuation among price indices based on Granger causality network. Phys. A: Stat. Mech. Its Appl. 2018, 506, 36-49. [CrossRef]

38. Huang, C.; Wen, S.; Li, M.; Wen, F.; Yang, X. An empirical evaluation of the influential nodes for stock market network: Chinese A-shares case. Finance Res. Lett. 2021, 38, 101517. [CrossRef]

39. Granger, C.; Granger, C.; Granger, C.; Clive, W.; Granger, C.; Hastie, T.; Tibshirani, R.; Friedman, J. Investigationg causal relations by econometric models: Cross spectral methods. Econom. J. Econom. Soc. 1969, 37, 424-438.

40. Albert, R.; Jeong, H.; Barabasi, A.L. Error and attack tolerance of complex networks. Nature 2000, 406, 378-382. [CrossRef] [PubMed] 